\title{
Relationship between Size of Cloud Ice and Lightning in the Tropics
}

\author{
Deen Mani Lal, ${ }^{1}$ Sachin D. Ghude, ${ }^{1}$ Jagvir Singh, ${ }^{2}$ and Suresh Tiwari ${ }^{1}$ \\ ${ }^{1}$ Indian Institute of Tropical Meteorology, Pune 411008, India \\ ${ }^{2}$ Ministry of Earth Sciences, Lodhi Road, New Delhi 110060, India \\ Correspondence should be addressed to Deen Mani Lal; dmlal@tropmet.res.in
}

Received 25 November 2013; Accepted 1 February 2014; Published 20 March 2014

Academic Editor: Pavan S. Kulkarni

Copyright (c) 2014 Deen Mani Lal et al. This is an open access article distributed under the Creative Commons Attribution License, which permits unrestricted use, distribution, and reproduction in any medium, provided the original work is properly cited.

\begin{abstract}
The association of lightning flashes with mean cloud ice size over continental and oceanic region in the tropical areas has been analyzed using the observations from various satellite platforms (MODIS, TRMM, and LIS) for the period 2000-2011. We found that frequency of lightning in general is higher over the continental region compared to oceanic region, whereas larger size of cloud ice is observed over the oceanic regions compared to the continental regions. Relationship between lighting and cloud ice size shows similar features over both continental and oceanic regions. For the first time, we show that total lighting increases with increase in the cloud ice size; attends maximum at certain cloud ice size and then decreases with increase in cloud ice size. Maximum lightning occurred for the mean cloud ice size of around 23-25 $\mu \mathrm{m}$ over the continental region and mean cloud ice size of around 24-28 $\mu \mathrm{m}$ over the oceanic region. Based on our observation we argue that the relation between lightning and mean cloud ice size follow the curve linear pattern, and not linear.
\end{abstract}

\section{Introduction}

Generation of lightning in atmosphere is still a matter of debate. It is a commonly established fact that ice is a key element to generate and separate the positive and negative charges inside the cloud which assists formation of lightning in the atmosphere [1]. During the occurrence of deep convection, water vapors are uplifted and condensed to form the deferent sizes of noninductive hydrometers (ice crystal, hail, drops, etc.); afterwards they are evaporated/sublimated and dispersed zonally and meridionally in the upper troposphere [2]. During upward motion, hydrometers collide with each other generating the charge on ice crystals, graupel, and liquid water $[3,4]$. Some of the earlier studies $[3,5]$ have shown that approximately $5 \times 10^{-4}$ e.s.u. $(0.17 \mathrm{pC})$ charges are transferred per collision between the crystals and graupels of radius approximately $50 \mu \mathrm{m}$. This activity mostly takes place at the height where the temperature is colder than $-10^{\circ} \mathrm{C}[6]$. Similarly, in other studies based on field measurement the charge density around 1 to $10 \mathrm{C} / \mathrm{km}^{3}$ at the levels between the isotherms of -10 to $-25^{\circ} \mathrm{C}$ have been reported [7]. Carey and Rutledge [8], Petersen et al. [9, 10], and Dye et al. [11] have found that strong updraft and production of significant lightning occurs at the height where the temperature is in between $0^{\circ} \mathrm{C}$ to $-40^{\circ} \mathrm{C}$. It is also believed that most of the noninductive charges inside the thunderstorm (due to rebounding collisions between graupel and ice crystals in the presence of super-cooled liquid water) are generated in this temperature region [4, 12-18]. The separation of the charge among the particles inside a cloud depends on the relative motion of hydrometers, whereas the rate of charge transfer and polarity depends on the size of particle, temperature and the liquid water content [19-21]. In addition, charges are also generated on crystal during condensation, evaporation, and sublimation/melting of ice. The rapid growth of electrification has been reported when cloud particles are frozen and form the ice during updraft $[22,23]$. Laboratory experiment [3] showed that graupel pellets gain much more charges if graupels are growing by riming and collide with ice. Some laboratory experiment also showed that during freezing of distilled water very small negative charges are generated, whereas during melting much larger negative charges are 
generated [24,25], but this effect could not be observed when water is contaminated.

Aerosol also affects the cloud ice concentration and its size by reducing the mean droplet size, which enhances the ice concentration in the region where temperature is less than zero [26]. Takahashi [27] found that increasing tendency of lightning flashes is positively correlated with increasing concentration of cloud ice as well as its size. Sherwood et al. [28] reported that occurrence of maximum lightning is associated with small size of cloud ice. In another study, decreasing size of cloud ice with increasing the aerosol concentration has also been reported [29].

In recent study over central India [30] a positive correlation has been found between ice concentration and lightning during premonsoon and monsoon seasons, whereas Deierling et al. [1] reported significant correlation between both precipitation and nonprecipitation ice mass with total lightning over Northern Alabama and Colorado/Kansas. Similar relation between lightning and cloud ice masses has also been reported in other field observations $[1,10,17,31-$ 34]. The combined effect of aerosol with thermodynamic effect over India [35] and threefold enhancement of cloudto-ground lightning flash density over Houston, Texas [36], raises the issue of pollution or heat island effect as a cause. As ice is a form of frozen cloud drops above the freezing level during deep convection, some results reported positive relation of lightning with strong updraft [11, 37-39].

Sizes of cloud ice represent the meteorological condition, aerosol effect, atmospheric dynamics, and are closely related to the cloud electrification and lightning discharge. It is still not clear whether small or large ice sizes increase the lightning flashes. Sherwood et al. [28] reported that small ice generate more lightning, whereas less cloud electrification in small cloud ice area is also reported $[18,40]$. In this study we have presented the relationship between size of cloud ice and lightning flashes on global scale (over tropical regions). Lightning flashes and effective radius of cloud ice are considered over both continental as well as oceanic region.

\section{Data}

In this study monthly mean cloud effective radius of ice phase (cloud particle size) (QA-W) from Moderate Resolution Imaging Spectroradiometer (MODIS) Level-3, cloud ice concentration from 3A12 version 6, and area averaged lightning from Lightning Imaging Sensor (LIS) on board of Tropical Rainfall Measurement Mission's (TRMM) satellite for the period of 2000-2011 data sets have been used for analysis. MODIS Level-3 was first launched on 18 December, 1999, on board the Terra platform and subsequently on 4 May, 2002, on board the Aqua platform, which is uniquely designed (high spatial resolution, wide spectral range, and near daily global coverage) to observe and monitor cloud effective radius and other Earth changes. We have used MODIS $1^{\circ} \times 1^{\circ}$ gridded level-3 monthly averaged cloud particle size from Terra platform (2000-2011) over continental region shown in Figure 1(d) as L1 [lat. (-35)-(-22), long. $(-67)-(-47)$ ], L2 [lat. (-12)-(-8), long. 9-29], and L3 [lat. 24-34, long.
68-83] in our analysis. Similarly, we used MODIS $1^{\circ} \times 1^{\circ}$ gridded level-3 monthly average cloud particle size data set from Aqua (2002-2011) over the oceanic region shown in Figure 1(d) as O1 [lat. (-32)-(-20), long. $(-146)-(-126)$ ], O2 [lat. 12-22, long. 49-73], and O3 [lat. 0-18, long. 124149]. We have also used MODIS, Terra platform data set, for the period of 2000-2001 for oceanic region. The agreement between MODIS monthly average cloud particle size data product from Terra and Aqua is observed to be $90 \%$ ( $R=$ 0.95 ) suggesting that both data sets are quite consistent. TRMM Microwave Instrument (TMI) profiling gives global vertical hydrometer profiles and surface rainfall mean on $0.5^{\circ} \times 0.5^{\circ}$ grid resolution. This data set is available at TRMM Online Visualization and Analysis System (TOVAS) webbased interface (http://gdatal.sci.gsfc.nasa.gov/daac-bin/G3/ gui.cgi?instanceid=TRMM_Monthly). We have used area average monthly vertical profile of cloud ice concentration retrieved by $3 \mathrm{~A} 12$ algorithm over the continental region (L1, $\mathrm{L} 2$, and $\mathrm{L} 3$ ) and oceanic region ( $\mathrm{O} 1, \mathrm{O} 2$, and $\mathrm{O} 3)$. We have also used lightning data from LIS which is a science instrument on board the TRMM observatory launched on 28 November, 1997. The detection efficiency of LIS is more than $80 \%$ in both daytime and nighttime with resolution (4 to $7 \mathrm{~km}$ ) over a large region $(600 \times 600 \mathrm{~km})$ of the Earth's surface for total lightning (i.e., intracloud + cloud-to-ground) [41].

2.1. Selection of Study Area. Figures 1(a) and 1(b) show the example of spatial distribution of size of cloud ice and lightning, respectively, for the year 2005. Year 2005 is neither drought year nor very heavy rainfall year. It is considered as normal rainfall year [42]. In order to study the association between size of cloud ice and lightning, we have selected three regions over the continental region as L1, L2, and L3 and over the ocean as $\mathrm{O} 1, \mathrm{O} 2$, and $\mathrm{O} 3$ shown in Figure 1(d). We have used 12 years $(2000-2011)$ of monthly cloud ice size and lightning data over the study area (L1, L2, L3 and O1, O2, O3) for analysis.

\section{Results}

3.1. Spatial Distribution of Cloud Ice Size and Lightning. Figure 1 shows the spatial and seasonal pattern of lightning and cloud effective radius (cloud particle/ice size) over the tropical regions for the year 2005. A clear spatial change in lightning and cloud ice can be seen in Figure 1. It is interesting to note from Figure 1 that frequency of lightning in general is higher over the continental region compared to oceanic region. The annual average lightning flashes over the areas L1, L2, and L3 are generally greater than 500 flashes $/ \mathrm{km}^{2} /$ month, whereas over the areas O1, O2, and $\mathrm{O} 3$ are less than 25 flashes $/ \mathrm{km}^{2} /$ months. On the other hand, larger size of cloud ice is observed over oceanic region compared to continental regions. The average cloud ice size is greater than $30 \mu \mathrm{m}$ (some places more than $40 \mu \mathrm{m}$ ) over the oceanic region (O1, O2, and $\mathrm{O} 3$ ) and less than $25 \mu \mathrm{m}$ over the selected areas (L1, L2, and L3) on continental region. During spring months (March, April, and May; MAM), intense lightning can be seen (Figure 1(d)) over the continental 


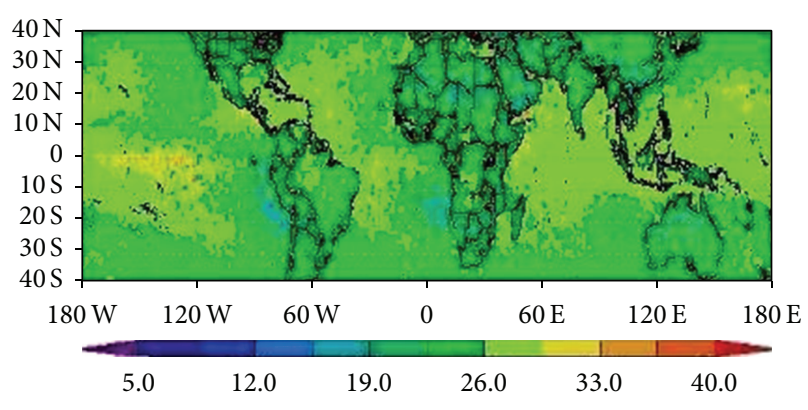

(a)

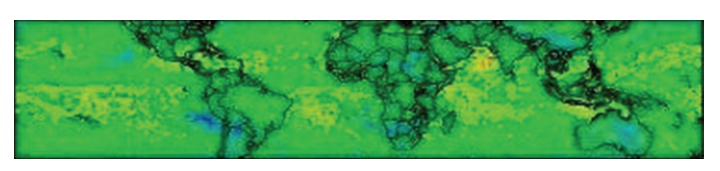

(c)

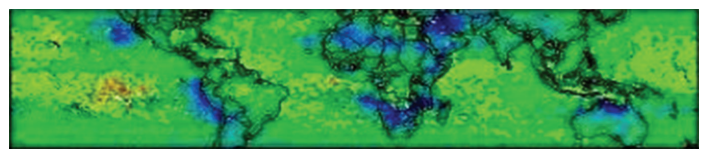

(e)

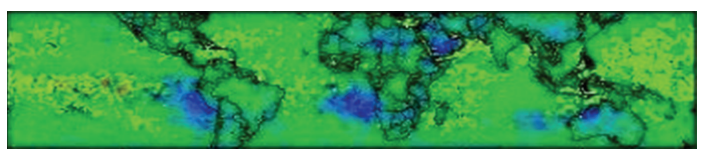

(g)

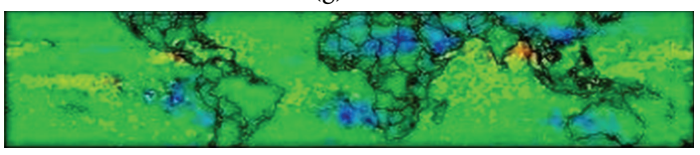

$\begin{array}{lllllllllll}10 & 13 & 16 & 19 & 22 & 25 & 28 & 31 & 34 & 37 & 40\end{array}$

(i)

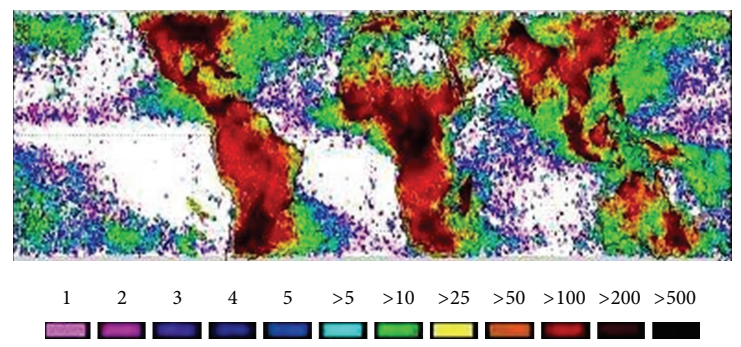

(b)

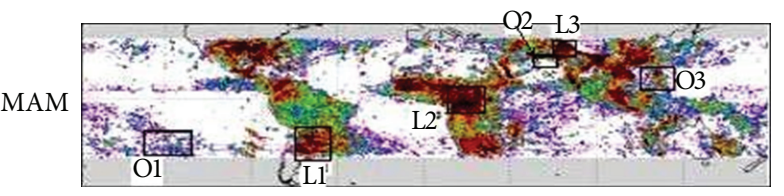

(d)

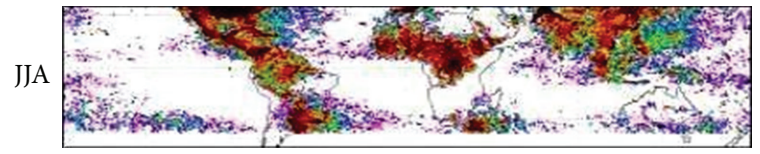

(f)

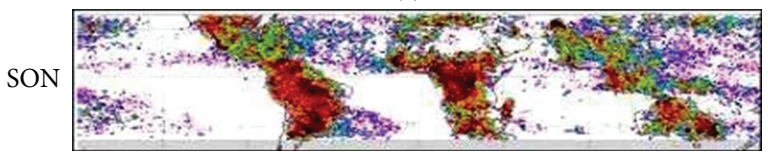

(h)

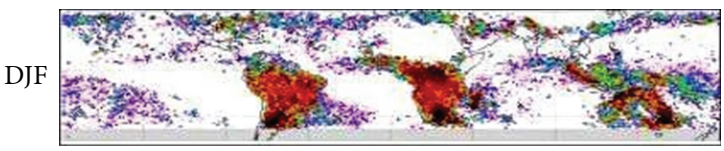

$\begin{array}{llllllllllll}1 & 2 & 3 & 4 & 5 & >5 & >10 & >15 & >25 & >50 & >100>150\end{array}$

(j)

FIGURE 1: Spatial distribution of (a) size of cloud ice and (b) lightning for the annual average and four seasons during 2005.

regions such as Uruguay and surrounding regions (East part of Argentina and south Brazil), central part of United State, Colombia, Central African Republican and surrounding region, Democratic Republican of Congo (DRC), eastern part of South Africa, India (Indo Gangetic plain and in some other parts), South-East part of China, Thailand, and Indonesia. Lightning frequency greater than 150 flashes $/ \mathrm{km}^{2} /$ month (Figure 1(d)) and the average effective cloud ice diameters between 22 and $25 \mu \mathrm{m}$ (Figure 1(c)) have been observed over these regions. The lightning frequency over Mexico, Guatemala, Nicaragua, Angola, Namibia, and the entire part of Brazil during spring months has been observed to be less than 25 flashes $/ \mathrm{km}^{2} /$ month (effective cloud ice diameter 28$31 \mu \mathrm{m}$ ). In comparison with continental regions (discussed above) the low lightning frequency $\left(<5\right.$ flashes $/ \mathrm{km}^{2} /$ month) and large ice particle size (31-40 $\mu \mathrm{m})$ has been observed over the oceanic region. In Figure 1, the similar features are also evident during summer monsoon (June, July, and August;
JJS), winter (December, January, and February; DJF), and fall months (September, October, and November; SON).

3.2. Relationship between Cloud Ice Size and Lightning. In order study the relationship between cloud ice size and lightning in detail we have analyzed the monthly mean cloud effective radius and total lightning (for the period 20002011) averaged over the continental (L1, L2, and L3) and oceanic (O1, O2, and O3) areas shown in Figure 1(d). Months corresponding to the cloud ice size between 19 and $34 \mu \mathrm{m}$ are grouped in the bin size of $1 \mu \mathrm{m}$ (we have considered all the months $(12 \times 12=144$ months) for frequency count). We have noticed that there were hardly any months in which monthly mean cloud ice size was less that $19 \mu \mathrm{m}$ or greater than $34 \mu \mathrm{m}$ during the study period. Lightning corresponding to each bin (of $1 \mu \mathrm{m}$ ) is then added to obtain total lightning for every $1 \mu \mathrm{m}$ bin between 19 and $34 \mu \mathrm{m}$. Figure 2 shows relationship between cloud ice size and lighting over the three different 


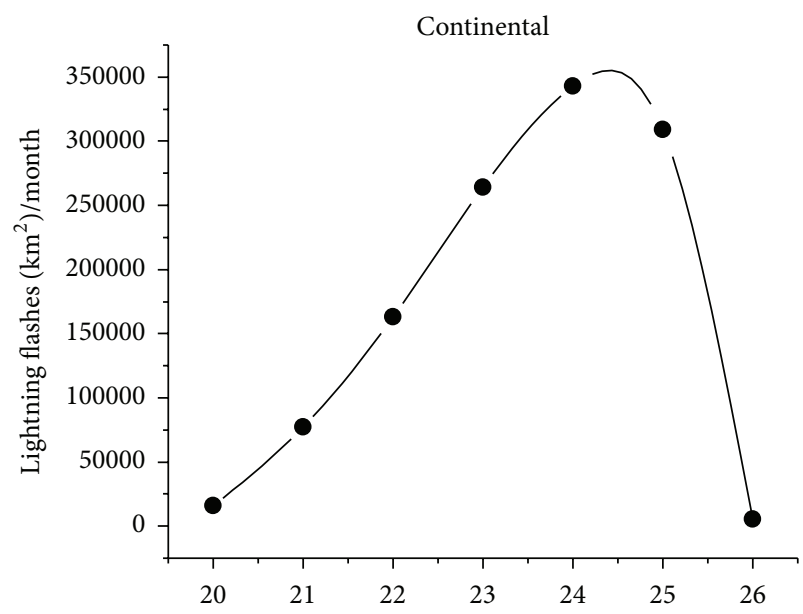

(A)

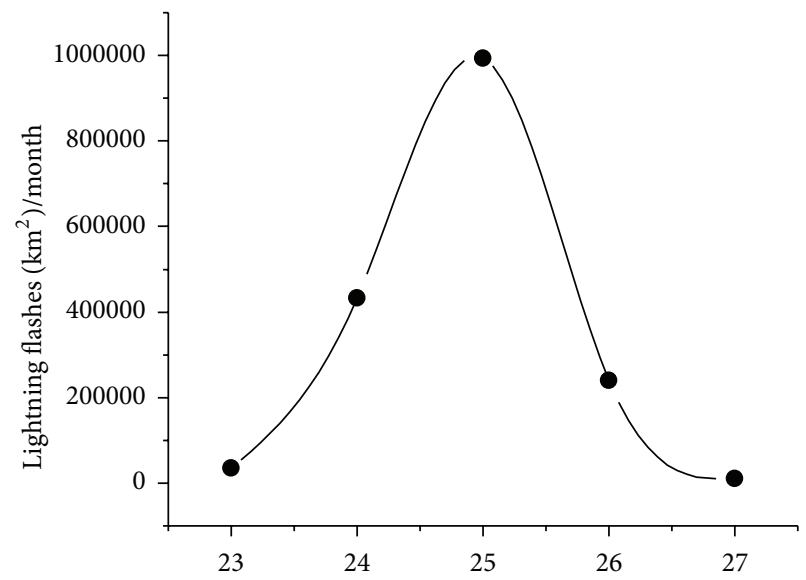

(B)

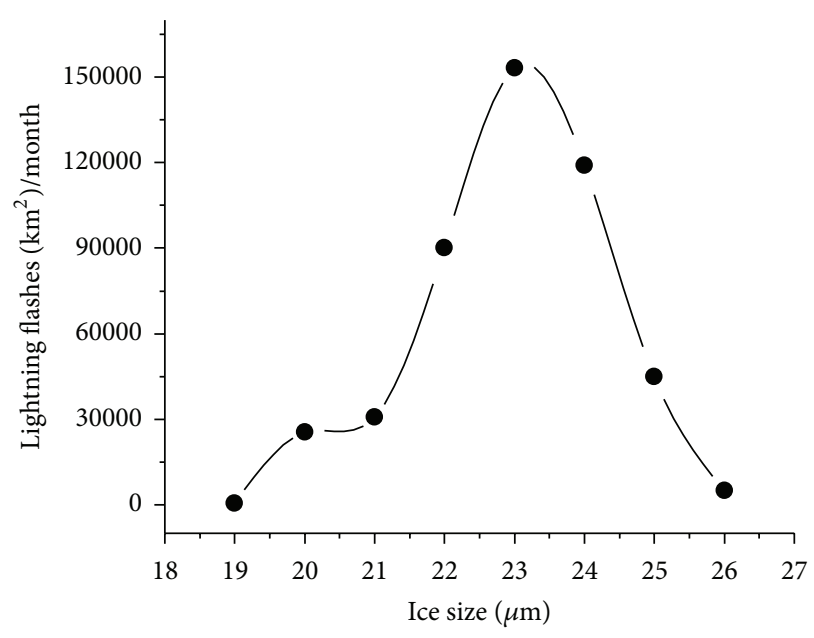

(C)

(a)

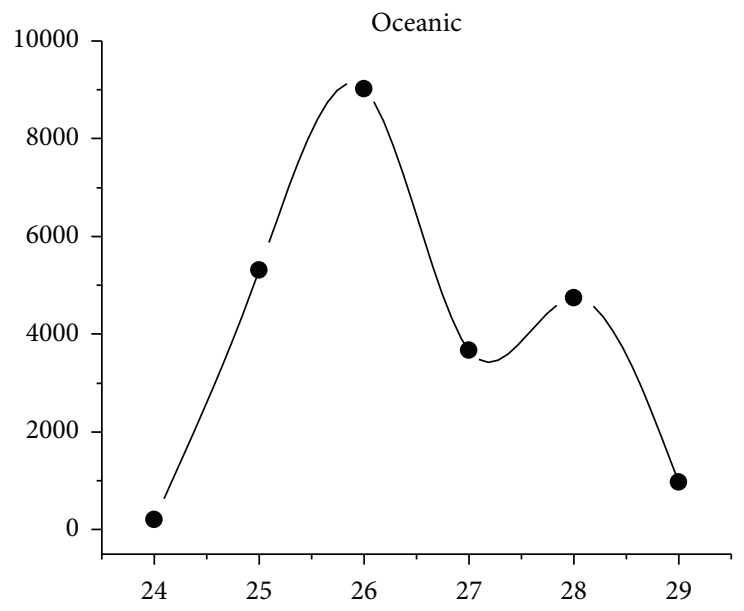

(A)

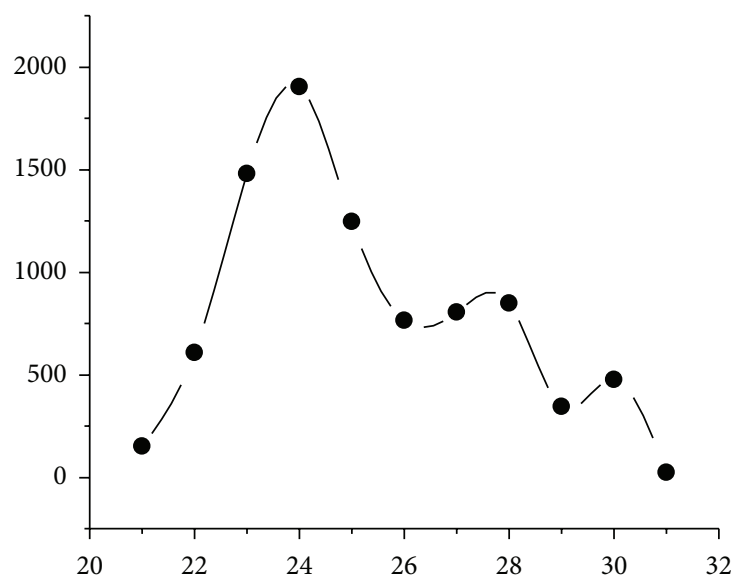

(B)

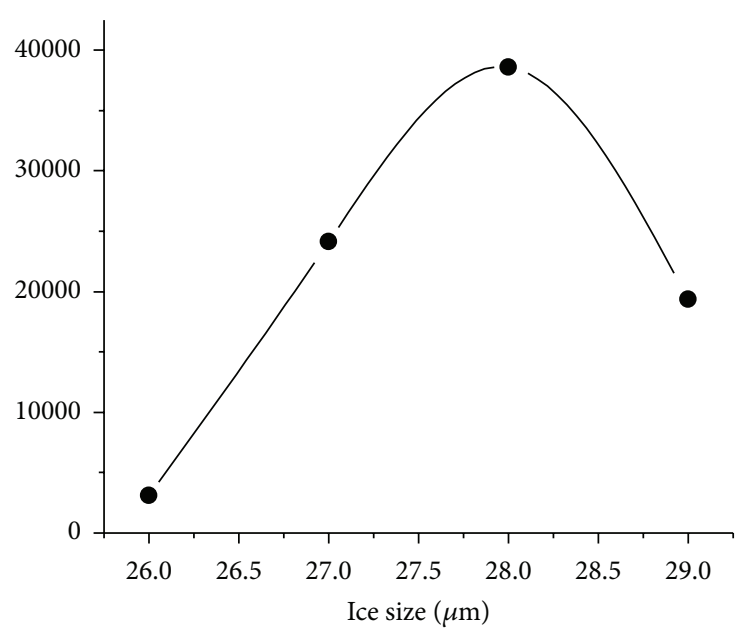

(C)

(b)

FIGURE 2: Relationship between mean cloud ice size and lightning over continental region (a) L1 (A), L2 (B), and L3 (C) and over oceanic region (b) $\mathrm{O} 1(\mathrm{~A}), \mathrm{O} 2(\mathrm{~B})$, and $\mathrm{O} 3(\mathrm{C})$. 


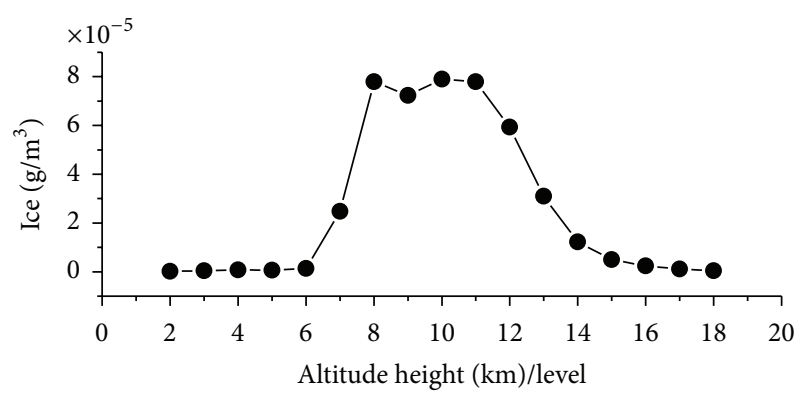

(a)

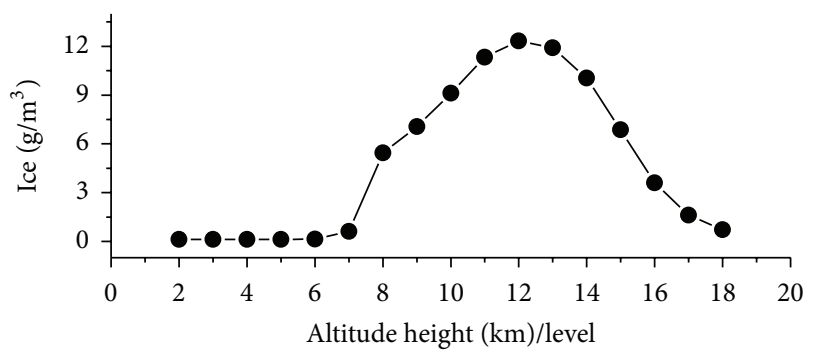

(b)

FIGURE 3: Distribution of cloud ice concentration as a function of altitude averaged during 2000-2011 period (a) over the continental region $\mathrm{L} 1$ and (b) oceanic region $\mathrm{O} 2$.

continental (Figure 2(a)) and oceanic regions (Figure 2(b)). It can be seen that relationship between lighting and cloud ice size shows similar pattern over both continental and oceanic regions. Maximum lightning occurred for the mean ice cloud sizes of 24,25 , and $23 \mu \mathrm{m}$ over the continental regions L1, L2, and L3, respectively. Similarly, over the oceanic regions $\mathrm{O} 1, \mathrm{O} 2$, and $\mathrm{O} 3$ maximum lightning occurred for the slightly greater mean cloud ice size of 26,24 , and $28 \mu \mathrm{m}$, respectively. It is interesting to note from Figure 2 that total lighting increases with increase in the cloud ice size, attains maximum at certain cloud ice size, and after that starts decreasing with increasing cloud ice size.

In order to understand this relationship we have analyzed vertical distribution of cloud ice concentration and relationship between cloud size with ice concentration over the continental and oceanic region. Figures 3(a) and 3(b) show the cloud ice concentration at different altitude averaged during 2000-2011 period over the continental region L1 and oceanic region $\mathrm{O} 2$, respectively. It can be seen that ice concentration increases from altitude of $6 \mathrm{~km}$, attends maximum concentration around 8-11 km over L1 and 10-14 km over O2 region, and decreases nearly to zero concentration at $18 \mathrm{~km}$. Figure 4 shows the distribution of cloud ice concentration as a function of mean cloud size at an altitude of $12 \mathrm{~km}$ (near to same height) over $\mathrm{L} 1$ and $\mathrm{O} 2$ regions, respectively. It can be seen from Figure 4 that ice concentration over L1 and $\mathrm{O} 2$ regions increases with respect to ice size up to $24 \mu \mathrm{m}$, attends maximum concentration at $24 \mu \mathrm{m}$, and ice concentration decreases with ice size above $24 \mu \mathrm{m}$. Similar relationship between ice concentration and ice size is also seen for the altitudes ranged between 8 and $14 \mathrm{~km}$ (not shown here). The charge is generated due to growth of ice size by condensation (deposition, combination of collection, etc.) and collision

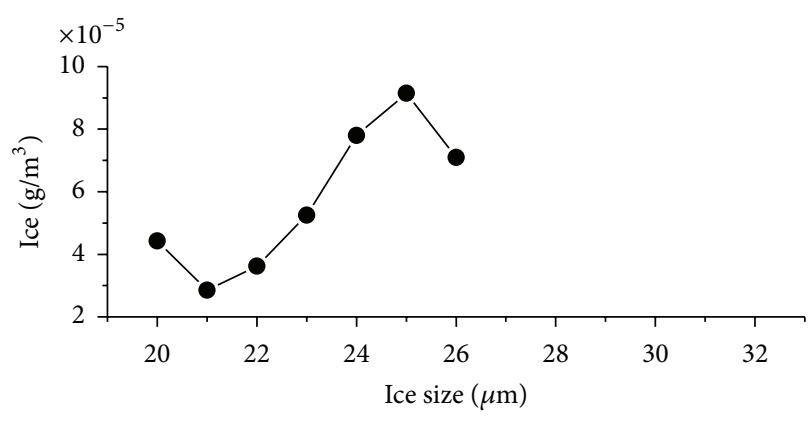

(a)

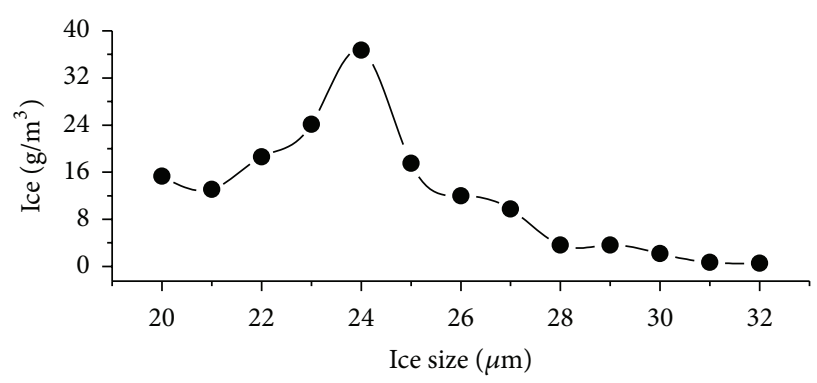

(b)

Figure 4: Relation between mean cloud ice size and cloud ice concentration averaged during 2000-2011 period at $12 \mathrm{~km}$ altitude (a) over the continental region $\mathrm{L} 1$ and (b) oceanic region $\mathrm{O} 2$.

among them during upward motion [41, 43]. This process enhances the electric filed inside the cloud and generate lightning. During convection, cloud ice grows its size by combination of collection and condensation or deposition. The increasing ice concentration with respect to mean ice size from 19 to $24 \mu \mathrm{m}$ in Figure 4 can be attributed to the growth of ice size. Therefore, generated charge (due to collision and condensation) increases with increasing the ice concentration and attends the maximum charge with the maximum ice concentration at $24 \mu \mathrm{m}$ inside the cloud. Hence, increasing lightning frequency with increasing the ice concentration with respect to ice size from 19 to $24 \mu \mathrm{m}$ with maximum lightning at $24 \mu \mathrm{m}$ can be seen in Figure 2. Takahashi [27] has also found increase in lightning with increase in the ice concentration and ice size, compliments to our results. The latent heat is generated during condensation or deposition increases the updraft velocity of the hydrometers, which enhances the hydrometers concentration at high altitude (Figure 3 ) as well as electric filed inside the cloud. Ziegler and MacGorman [44] and Dey et al. [11] found that altitude range of about 7$10 \mathrm{~km}$ is favorable for electrification of clouds for generating lightning discharge. This is consistent with Figure 3 where we observed maximum ice concentration between 8 and $14 \mathrm{~km}$ altitude ranges. It can also be seen from Figure 3 that although maximum ice concentration over both land and oceanic regions are found approximately in same altitude range (8$14 \mathrm{~km}$ ), yet less lightning occurs over oceanic region. It might be due to weak updraft velocity in mix-phase region over ocean as compared to continental region.

On the other hand, increased size of cloud ice increases its terminal velocity and thereby reduces the uplift velocity. 
Therefore, larger particle descends isothermally towards the ground and begins to melt [45]. In this case charge with opposite polarity is also generated on hydrometer [43], however, unable to generate the charge to produce the lightning due to slow sublimation and low concentration of ice. Takahashi [4] also showed that the charge transfers per collision slow down with increase in ice diameter size. Therefore, the negative relationship between total lightning and mean cloud ice size which is greater than $26-28 \mu \mathrm{m}$ instead of positive correlation for the size less than $19-25 \mu \mathrm{m}$ can be seen in Figure 2 . It is reasonable to conclude from Figures 2, 3, and 4 that the highest mean ice size of around $24 \mu \mathrm{m}$ contributes to maximum ice concentration in the altitude range between 8 and $14 \mathrm{~km}$ and therefore results in the maximum lightning (over land and oceanic regions) for ice size of around 23$26 \mu \mathrm{m}$ (seen in Figure 2). These imply that the relationship between mean ice size and lightning is curve linear.

\section{Conclusions}

In this work, we have analyzed 12 years (2000-2011) of monthly mean satellite observations of lightning from LIS, ice concentration from TRMM (3A12, V6), and effective diameter of cloud ice form MODIS over the Tropical Ocean and continental regions. We have examined the association of lightning flashes with mean ice size over these regions. A clear spatial change in lighting and cloud ice size from spring to winter season is seen. In general, total lightning is observed higher over the continental regions as compared to the lightning observed over oceanic region, whereas mean cloud ice size is observed higher over the oceanic region compared to the continental region during all the seasons. It is observed that the relationship between lightning and mean cloud ice size is same over both continental and oceanic regions. It is also observed that maximum lightning occurred for the mean cloud ice size of around $23-25 \mu \mathrm{m}$ over the continental region and mean cloud ice size of around 24$28 \mu \mathrm{m}$ over the oceanic region. However, for the first time, we found that relationship between lightning and mean cloud ice size follows the curve linear pattern and is not linear. We found that total lighting increases with increase in the cloud ice size and attends maximum at certain cloud ice size, then lightning decreases with increasing cloud ice size. The altitude profile show increase in ice concentration from $6 \mathrm{~km}$, attends maximum concentration around $8-11 \mathrm{~km}$ over continent and 10-14 km over oceanic region, and decreases to zero concentration at around $18 \mathrm{~km}$. Ice concentration within this region shows maximum around $24 \mu \mathrm{m}$. This concludes that maximum lightning observed around $23-25 \mu \mathrm{m}$ over the continental region and $24-28 \mu \mathrm{m}$ over the oceanic region is associated with the large ice concentration at around $24 \mu \mathrm{m}$.

\section{Conflict of Interests}

The authors declare that there is no conflict of interests regarding the publication of this paper.

\section{Acknowledgments}

The authors are gratefully thankful to Earth Observatory System and Earth System Science Program who provided the TRMM data. The authors also acknowledge the MODIS mission scientists and associated NASA personnel for the production of the data used in this research.

\section{References}

[1] W. Deierling, W. A. Petersen, J. Latham, S. Ellis, and H. J. Christian, "The relationship between lightning activity and ice fluxes in thunderstorms," Journal of Geophysical Research: Atmospheres, vol. 113, no. D15, Article ID D15210, 2008.

[2] R. E. Newell, Y. Zhu, E. V. Browell, W. G. Read, and J. W. Waters, "Walker circulation and tropical upper tropospheric water vapor," Journal of Geophysical Research: Atmospheres, vol. 101, no. D1, pp. 1961-1974, 1996.

[3] S. E. Reynolds, M. Brook, and M. F. Gourley, "Thunderstorm charge separations," Journal of Meteorology, vol. 14, pp. 426-436, 1957.

[4] T. Takahashi, "Riming electrification as a charge generation mechanism in thunderstorms," Journal of the Atmospheric Sciences, vol. 35, pp. 1536-1548, 1978.

[5] D. G. Evans and W. C. A. Hutchinson, "The electrification of freezing water droplets and of colliding ice particles," Quarterly Journal of the Royal Meteorological Society, vol. 89, no. 381, pp. 370-375, 1963.

[6] S. E. Reynolds, "Thunderstorm-precipitation growth and electrical-charge generation," Bulletin of the American Meteorological Society, vol. 34, pp. 117-123, 1953.

[7] P. R. Krehbiel, M. Brook, and R. A. McCrory, "An analysis of the charge structure of lightning discharges to ground," Journal of Geophysical Research: Oceans, vol. 84, no. 5, pp. 2432-2456, 1979.

[8] L. D. Carey and S. A. Rutledge, "A multiparameter radar case study of the microphysical and kinematic evolution of a lightning producing storm," Meteorology and Atmospheric Physics, vol. 59, no. 1-2, pp. 33-64, 1996.

[9] W. A. Petersen, S. A. Rutledge, and R. E. Orville, "Cloud-toground lightning observations from TOGA COARE: selected results and lightning location algorithms," Monthly Weather Review, vol. 124, no. 4, pp. 602-620, 1996.

[10] W. A. Petersen, S. A. Rutledge, R. C. Cifelli, B. S. Ferrier, and B. F. Smull, "Shipborne dual-Doppler operations during TOGA COARE: integrated observations of storm kinematics and electrification," Bulletin of the American Meteorological Society, vol. 80, no. 1, pp. 81-96, 1999.

[11] J. E. Dye, W. P. Winn, J. J. Jones, and D. W. Breed, "The electrification of New Mexico thunderstorms. 1. Relationship between precipitation development and the onset of electrification," Journal of Geophysical Research: Atmospheres, vol. 94, no. D6, pp. 8643-8656, 1989.

[12] S. E. Reynolds and M. Brook, "Correlation of the initial electric field and the radar echo in thunderstorms," Journal of Meteorology, vol. 13, no. 4, pp. 376-380, 1956.

[13] E. R. Jayaratne, C. P. R. Saunders, and J. Hallett, "Laboratory studies of the charging of soft- hail during ice crystal interactions," Quarterly Journal of the Royal Meteorological Society, vol. 109, no. 461, pp. 609-630, 1983. 
[14] E. R. Williams, “The tripole structure of thunderstorms," Journal of Geophysical Research: Atmospheres, vol. 94, no. D11, pp. 13151-13167, 1989.

[15] C. P. R. Saunders and S. L. Peck, "Laboratory studies of the influence of the rime accretion rate on charge transfer during crystal/graupel collisions," Journal of Geophysical Research: Atmospheres, vol. 103, no. D12, pp. 13949-13956, 1998.

[16] E. R. Mansell, D. R. MacGorman, C. L. Ziegler, and J. M. Straka, "Charge structure and lightning sensitivity in a simulated multicell thunderstorm," Journal of Geophysical Research: Atmospheres, vol. 110, no. D12, pp. 1-24, 2005.

[17] J. Latham, W. A. Petersen, W. Deierling, and H. J. Christian, "Field identification of a unique globally dominant mechanism of thunderstorm electrification," Quarterly Journal of the Royal Meteorological Society, vol. 133, no. 627, pp. 1453-1457, 2007.

[18] E. J. Zipser, "Deep cumulonimbus cloud systems in the tropics with and without lightning," Monthly Weather Review, vol. 122, no. 8, pp. 1837-1851, 1994.

[19] E. R. Williams, R. Zhang, and J. Rydock, "Mixed-phase microphysics and cloud electrification," Journal of the Atmospheric Sciences, vol. 48, no. 19, pp. 2195-2203, 1991.

[20] R. G. Pereyra, E. E. Avila, N. E. Castellano, and C. P. R. Saunders, "A laboratory study of graupel charging," Journal of Geophysical Research: Atmospheres, vol. 105, no. D16, pp. 20803-20812, 2000.

[21] C. P. R. Saunders, H. Bax-Norman, C. Emersic, E. E. Avila, and N. E. Castellano, "Laboratory studies of the effect of cloud conditions on graupel/crystal charge transfer in thunderstorm electrification," Quarterly Journal of the Royal Meteorological Society, vol. 132, no. 621, pp. 2653-2673, 2006.

[22] V. N. Bringi, I. J. Caylor, J. Turk, and L. Liu, "Microphysical and electrical evolution of a convective storm using multiparameter radar and aircraft data during CaPE," in Proceedings of the 26th International Conference on Radar Meteorology, pp. 312-314, American Meteorological Society, May 1993.

[23] J. E. Dye, "Early electrification and precipitation development in a small, isolated Montana cumulonimbus," Journal of Geophysical Research: Atmospheres, vol. 91, no. D1, pp. 1231-1247, 1986.

[24] J. E. Dinger and R. Gunn, "Electrical effects associated with a change of state of water," Terrestrial Magnetism and Atmospheric Electricity, vol. 51, no. 4, pp. 477-494, 1946.

[25] M. Stolzenburg, T. C. Marshall, W. D. Rust, and B. F. Smull, "Horizontal distribution of electrical and meteorological conditions across the stratiform region of a mesoscale convective system," Monthly Weather Review, vol. 122, no. 8, pp. 1777-1797, 1994.

[26] D. Rosenfeld, U. Lohmann, G. B. Raga et al., "Flood or drought: how do aerosols affect precipitation?" Science, vol. 321, no. 5894, pp. 1309-1313, 2008.

[27] T. Takahashi, "Thunderstorm electrification-a numerical study," Journal of the Atmospheric Sciences, vol. 41, no. 17, pp. 2541-2558, 1984.

[28] S. C. Sherwood, V. T. J. Phillips, and J. S. Wettlaufer, "Small ice crystals and the climatology of lightning," Geophysical Research Letters, vol. 33, no. 5, Article ID L05804, 2006.

[29] S. C. Sherwood, "Aerosols and ice particle size in tropical cumulonimbus," Journal of Climate, vol. 15, no. 9, pp. 1051-1063, 2002.

[30] D. M. Lal and S. D. Pawar, "Relationship between rainfall and lightning over central Indian region in monsoon and premonsoon seasons," Atmospheric Research, vol. 92, no. 4, pp. 402-410, 2009.
[31] S. W. Nesbitt, E. J. Zipser, and D. J. Cecil, "A census of precipitation features in the tropics using TRMM: radar, ice scattering, and lightning observations," Journal of Climate, vol. 13, no. 23, pp. 4087-4106, 2000.

[32] W. Deierling, J. Latham, W. A. Petersen, S. M. Ellis, and H. J. Christian Jr., "On the relationship of thunderstorm ice hydrometeor characteristics and total lightning measurements," Atmospheric Research, vol. 76, no. 1-4, pp. 114-126, 2005.

[33] W. A. Petersen, H. J. Christian, and S. A. Rutledge, “TRMM observations of the global relationship between ice water content and lightning," Geophysical Research Letters, vol. 32, no. 14, Article ID L14819, 2005.

[34] K. C. Wiens, S. A. Rutledge, and S. A. Tessendorf, "The 29 June 2000 supercell observed during STEPS - part II: lightning and charge structure," Journal of the Atmospheric Sciences, vol. 62, no. 12, pp. 4151-4177, 2005.

[35] D. M. Lal and S. D. Pawar, "Effect of urbanization on lightning over four metropolitan cities of India," Atmospheric Environment, vol. 45, no. 1, pp. 191-196, 2011.

[36] S. M. Steiger, R. E. Orville, and G. Huffines, "Cloud-toground lightning characteristics over Houston, Texas: 19892000," Journal of Geophysical Research: Atmospheres, vol. 107, no. D11, pp. 2-13, 2002.

[37] E. J. Workman and S. E. Reynolds, "Electrical activity as related to thunderstorm cell growth," Bulletin of the American Meteorological Society, vol. 30, pp. 142-149, 1949.

[38] E. R. Williams and R. M. Lhermitte, "Radar tests of the precipitation hypothesis for thunderstorm electrification," Journal of Geophysical Research: Oceans, vol. 88, no. C15, pp. 10984-10992, 1983.

[39] S. A. Rutledge, E. R. Williams, and T. D. Keenan, "The Down Under Doppler and Electricity Experiment (DUNDEE): overview and preliminary results," Bulletin of the American Meteorological Society, vol. 73, no. 1, pp. 3-16, 1992.

[40] R. A. Black, J. Hellett, and C. R. P. Saunders, "Air craft study of precipitation and electrification," in Proceeding of the 17th Conference on Severe Local Storms and Conference on Atmospheric Electricity, pp. J20-J25, St. Louis, Mo, USA, October 1993.

[41] H. J. Christian, R. J. Blakeslee, S. J. Goodman et al., "The lightning imaging sensor," in Proceedings of the 11th International Conference on Atmospheric Electricity, pp. 746-749, Guntersville, Ala, USA, June 1999.

[42] Annual Climate Summary, IMD Government of India, 2005.

[43] J. P. Rydock and E. R. Williams, "Charge separation associated with frost growth," Quarterly Journal of the Royal Meteorological Society, vol. 117, no. 498, pp. 409-420, 1991.

[44] C. L. Ziegler and D. R. Macgorman, "Observed lightning morphology relative to modeled space charge and electric field distributions in a tornadic storm," Journal of the Atmospheric Sciences, vol. 51, no. 6, pp. 833-851, 1994.

[45] T. R. Shepherd, W. D. Rust, and T. C. Marshall, "Electric fields and charges near $0^{\circ} \mathrm{C}$ in stratiform clouds," Monthly Weather Review, vol. 124, no. 5, pp. 919-938, 1996. 

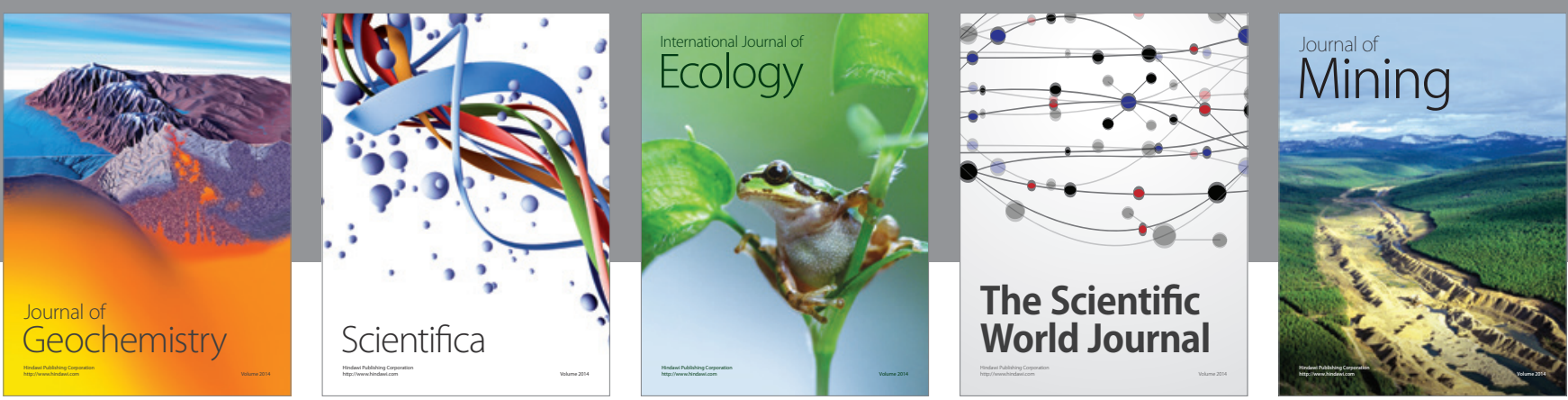

The Scientific World Journal
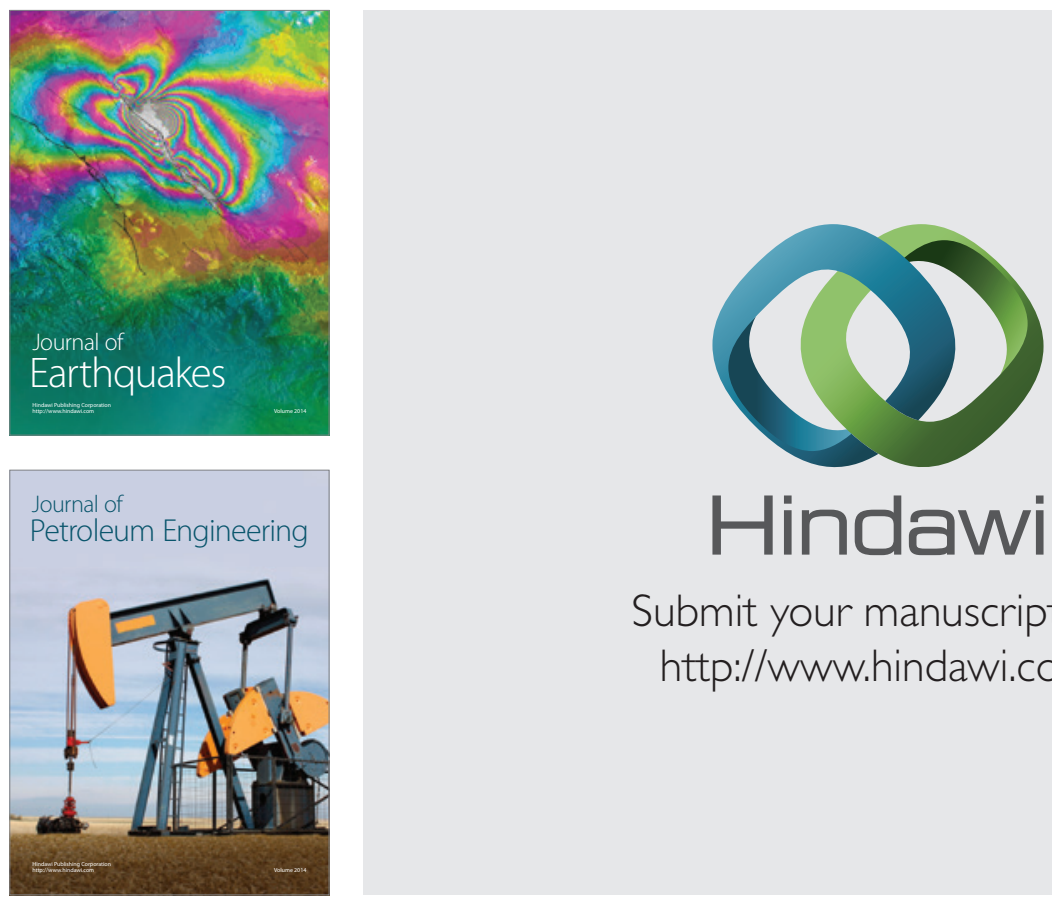

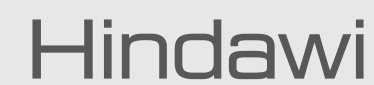

Submit your manuscripts at

http://www.hindawi.com
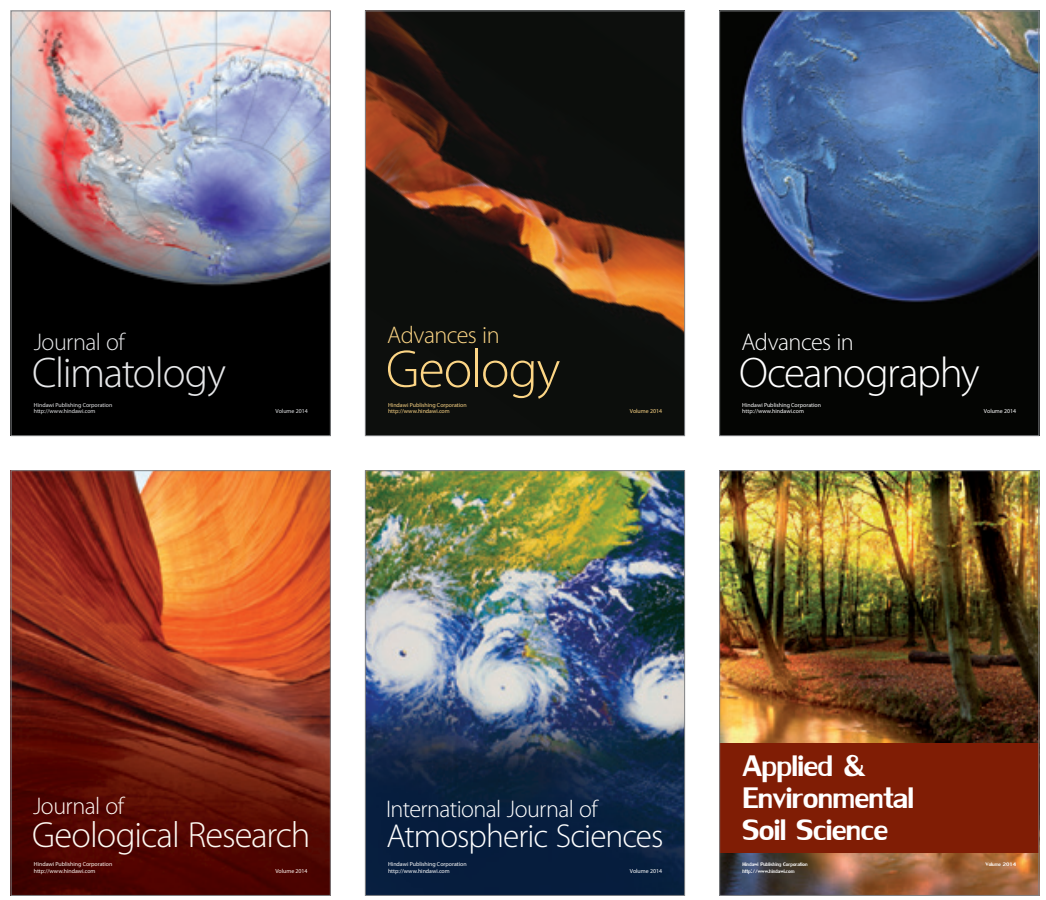
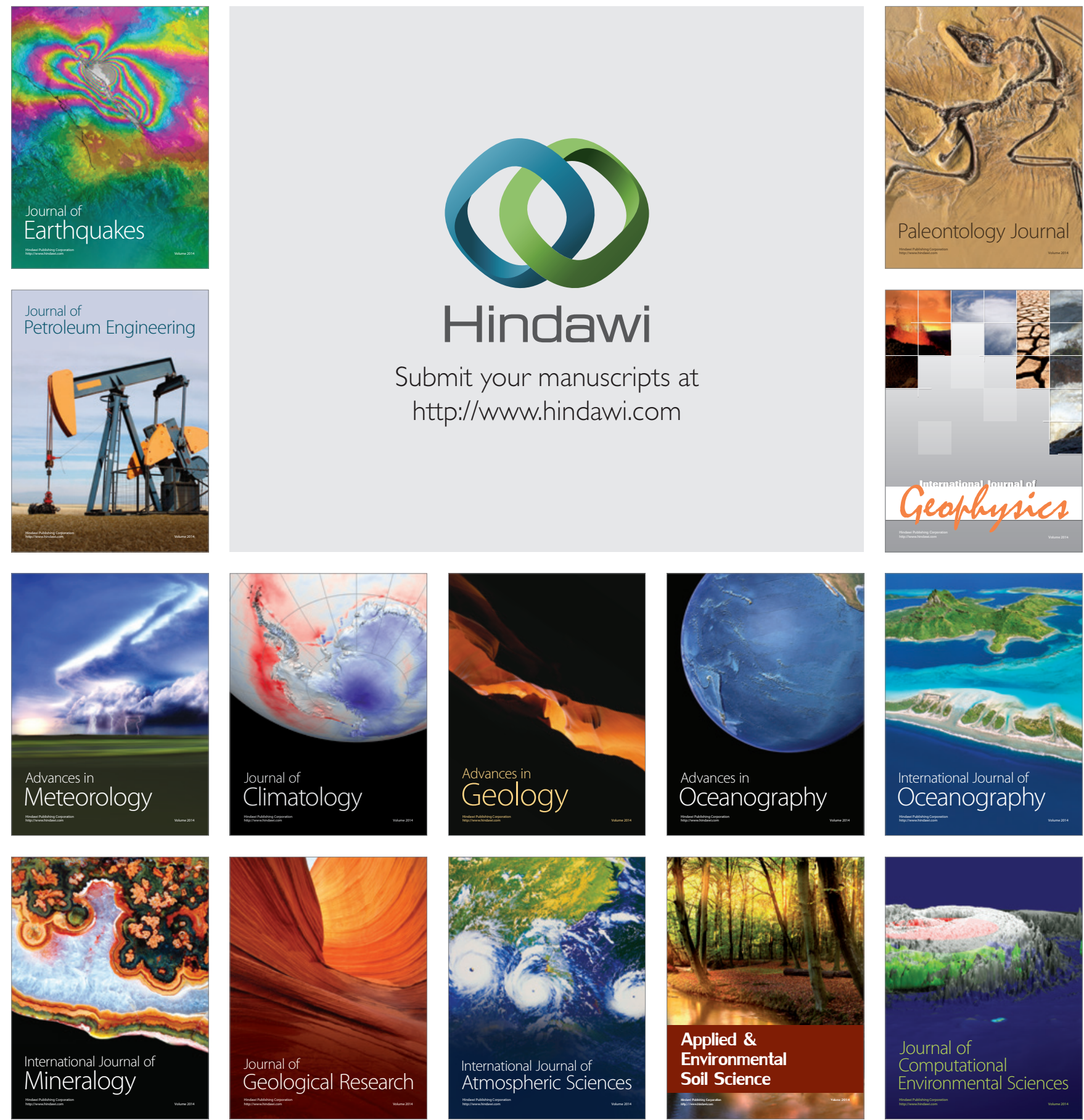